\title{
SMALL-FOR-GESTATIONAL AGE PREVALENCE RISK FACTORS IN CENTRAL APPALACHIAN STATES WITH MOUNTAIN-TOP MINING
}

\section{HAMID FERDOSI ${ }^{1,2}$, STEVE H. LAMM ${ }^{1,3,4}$, NANA AMA AFARI-DWAMENA ${ }^{1}$, ELISABETH DISSEN ${ }^{1}$, RUSAN CHEN ${ }^{5}, \mathrm{JI} \mathrm{LI}^{1,6}$, and MANNING FEINLEIB ${ }^{6}$}

${ }^{1}$ Center in Epidemiology and Environmental Health, LLC, Washington, D.C., USA

${ }^{2}$ George Washington University, Washington, D.C., USA

Milken Institute School of Public Health

${ }^{3}$ Johns Hopkins University Bloomberg School of Public Health, Baltimore, Maryland, USA

${ }^{4}$ Georgetown University, Washington, D.C., USA

School of Medicine (Pediatrics)

${ }^{5}$ Georgetown University, Washington, D.C., USA

Centers for New Designs in Learning and Scholarships

${ }^{6}$ Johns Hopkins University, Baltimore, Maryland, USA

School of Medicine

\begin{abstract}
Objectives: To identify risk factors for small-for-gestational age (SGA) for counties in central Appalachian states (Kentucky (KY), Tennessee (TN), Virginia (VA), and West Virginia (WV)) with varied coal mining activities. Material and Methods: Live birth certificate files (1990-2002) were used for obtaining SGA prevalence rates for mothers based on the coal mining activities of their counties of residence, mountain-top mining (MTM) activities, underground mining activities but no mountain-top mining activity (non-MTM), or having no mining activities (non-mining). Co-variable information, including maternal tobacco use, was also obtained from the live birth certificate. Adjusted odds ratios were obtained using multivariable logistic regression comparing SGA prevalence rates for counties with coal mining activities to those
\end{abstract}

\footnotetext{
This work was presented at the 2014 annual meeting of the American College of Epidemiology (ACE), Silver Spring, MD September 2014, 2nd OTIS/ENTIS International Conference of Teratology Information Specialists, Toronto, Canada September 2014, and 55th The Teratology Society annual meeting, Montreal, Canada July 2015.

Funding: this work was funded by the Appalachian Research Initiative for Environmental Sciences (ARIES) (sub-award 441693-19A81) through Virginia Tech. Grant manager: Michael Karmis, Ph.D.

Steve H. Lamm and Hamid Ferdosi are full-time employees of Center in Epidemiology and Environmental Health, LLC (CEOH) in Washington, D.C. This project derives from a $\mathrm{CEOH}$ research grant from the Appalachian Research Initiative for Environmental Sciences (ARIES). ARIES is operated by Virginia Tech and obtains its research funds from companies in the energy field, including coal, oil, and gas industries. Research projects derived from ARIES research grants are independently designed, conducted, interpreted and published by the scientific authors without the involvement of AIRES. Other than the CEOH research grants with ARIES, none of the authors have an actual or potential financial interest.

Received: June 15, 2016. Accepted: October 5, 2016.

Corresponding author: H. Ferdosi, Center in Epidemiology and Environmental Health, LLC, 3401 38th Street NW, Washington, D.C. 20016, USA (e-mail: Hamid@ceoh.com).
} 
without coal mining activities and comparing SGA prevalence rates for counties with coal mining activities for those with and without mountain-top mining activities. Comparisons were also made among those who had reported tobacco use and those who had not. Results: Both tobacco use prevalence and SGA prevalence were significantly greater for mining counties than for non-mining counties and for MTM counties than for non-MTM counties. Adjustment for tobacco use alone explained $50 \%$ of the increased SGA risk for mining counties and 75\% of the risk for MTM counties, including demographic pre-natal care co-variables that explained $75 \%$ of the increased SGA risk for mining counties and $100 \%$ of the risk for MTM. The increased risk of SGA was limited to the third trimester births among tobacco users and independent of the mining activities of their counties of residence. Conclusions: This study demonstrates that the increased prevalence of SGA among residents of counties with mining activity was primarily explained by the differences in maternal tobacco use prevalence, an effect that itself was gestational-age dependent. Self-reported tobacco use marked the population at the increased risk for SGA in central Appalachian states. Int J Occup Med Environ Health 2018;31(1):11-23

Key words:

Tobacco, Mining, Maternal smoking, Small for gestational age, Mountain-top mining, SGA prevalence

\section{INTRODUCTION}

Adverse community health metrics have been the characteristics of life in Appalachia for as long as records have been maintained. The Appalachia Regional Commission was established in 1965 to focus resources on elevating the health status of residents in Appalachia to that of the rest of the United States. Nonetheless, the health status of residents of Appalachia is still diminished. This study focuses on neonatal or infant health in the 4 central Appalachian states of Kentucky (KY), Tennessee (TN), Virginia (VA), and West Virginia (WV). Infant mortality data shows that the infant mortality for each of these 4 states is above the national mean and median [1].

Within the last decade, health studies have emerged to have examined the association of adverse community health metrics with residence in Appalachian counties and the presence or nature of coal mining activity [2-4]. These 4 states account for one-third of the U.S. coal production [5]. Although most Appalachian health studies have focused on adult health [6-9], a few have examined the health of newborns $[9,10]$. Ahern et al. [9] reported on birth defect rates with respect to mining activities, and Ahern et al. [10] reported on low birth weight prevalence with respect to mining activities.

Adequacy of fetal growth is a common public health concern, and the prevalence of small-for-gestational age (SGA) infants is a standard and primary growth mea- sure of newborn health in a population. It is preferred over low birth weight (LBW), as LBW is confounded by prematurity and SGA is not [11]. Small-for-gestational age is thus a direct measure of intrauterine growth retardation (IUGR), the outcome of concern, and is relevant across the full gestational age range of live births.

From the mid to the late 20th century, when survival rates of premature infants were low, the standard measures of adequate intrauterine life were the avoidance of prematurity (i.e., births prior to a gestational age of 37 weeks) and the avoidance of low birth weight (i.e., $<2500 \mathrm{~g}$ for a fullterm birth). In the beginning of the 21st century, attention focused on small-for-gestational age (SGA) as a more useful summary measure. Small-for-gestational age is defined as a birth weight below the 10th percentile birth weight for an infant of a specific gestational age (in weeks). Smallfor-gestational age gives recognition to the observation that the third trimester of pregnancy is the period of accelerated growth and that the expected "normal" weight is thus dependent on the gestational age of the newborn rather than independent of gestational age. Small-forgestational age has been chosen as the outcome variable of interest as it allows for the examination of the prevalence of IUGR, which is the outcome of concern, independent of gestational age.

A recent analysis of SGA prevalence in the 4-state Appalachian area (KY, TN, VA, and WV) showed the analysis, 
that did not include mining activity, that the SGA prevalence was most markedly influenced by tobacco use (odds ratio $(\mathrm{OR})=2.5)$ and that the effect changed markedly across the gestational age range of 22-44 weeks [12]. We now examine the 1990-2002 SGA prevalence in the 4-state area specifically with respect to the mining activity in the county of maternal residence taking into consideration both the issues of tobacco use and of gestational age.

\section{MATERIAL AND METHODS}

\section{Study population}

Data for the study population came from the 1990-2002 live birth certificate files for the 4 central Appalachian states (Kentucky, Tennessee, Virginia, and West Virginia) and were obtained from the National Center for Health Statistics with the approval of the 4 state departments of health. All data was from the 1989 revision of the U.S. live birth certificate; none of the data was from the 2003 revision. Data files included information on both newborns and parents with geographic location de-identified to state and county of maternal residence at the time of the infant's birth. Analyses were limited to singleton live births. The counties in the 4 study states had been categorized in Ahern et al. [9] as either having no mining activity (nonmining), having only underground mining activity and no surface or mountain-top mining activity (non-MTM), or having, in addition to underground mining activity, mountain-top mining activity (MTM). This classification of the counties was used in our analyses. The classification was similar to that based on the county-specific coal production data from the Energy Information Agency of the U.S. Department of Energy [5].

\section{Outcome measure}

Small-for-gestational-age (SGA) is a relative measure of fetal growth that relates the birth weight distribution to the gestational age, specifically a birth weight less than the 10th percentile of the birth weights recorded for that gestational age in weeks $[13,14]$. The determination of SGA is based on the recorded birth weight and the recorded gestational age and then compared to the cutoff value of the reference population. Each reference gives a set of cutoff values by each week of gestational life, sometimes separately by race, sometimes separately for gender [13,14].

The analyses presented here use the 10th percentile cutoff values for non-Hispanic white mothers, reported by Oken et al. (2003) [15]. The reference population was derived from the 1999-2000 U.S. birth certificate data from the National Center for Health Statistics Natality Data Sets (National Vital Statistics System Birth Data), thus using the same form as that of our study population [16]. There is little cross-over between the study and reference population as the white singleton birth population of the reference population (US, 1999-2000) comprises less than $0.5 \%$ of the study population (4 states, 1990-2002). Each 1990-2002 singleton live birth with gestational age 22-44 weeks for the 4 states was categorized as SGA or not, based on the cutoff values for non-Hispanic white mothers, reported by Oken et al. [15].

Our analysis was limited to the non-Hispanic white population as that was the population definition of Oken et al. [15]. Non-Hispanic white women comprised $98 \%$ of the maternal population in the mining counties and $94 \%$ of the maternal population in the non-mining counties. We had used the cutoff values for white (non-Hispanic) mothers, reported by Oken et al., that have been adjusted to child's gender [15].

\section{Co-variables or risk factors}

The birth certificate contains data on a limited number of potential co-variables. Co-variables extracted from the birth certificate form included variables of time (year of birth and gestational age) and space (place of maternal residence (state) and place of maternal birth (country)), maternal characteristics (marital status, age, race, 
Hispanic origin, and education), paternal characteristics (age, race, and education), pregnancy care (prenatal care adequacy, number of pre-natal visits, month when prenatal visits began), newborn characteristics (sex) and lifestyle factors (self-reported tobacco and alcohol use). All co-variables that entered the analysis had been recorded for at least $98 \%$ of the live births.

Place of maternal birth entered the analytic data set as a dichotomous variable (foreign or domestic), as did marital status (unmarried or married), tobacco use (yes or no), child sex (male or female), Hispanic ethnicity of mother (yes or no), maternal education ( $>12$ years of schooling or not), and pre-natal care adequacy (PCA) (adequate or not). Prenatal adequacy is a constructed co-variable that includes both trimester when prenatal visits were initiated and the number of prenatal visits, using a nomogram of the Institute of Medicine-modified Kessner criterion [17], and were recorded in the birth certificate data set. Maternal age entered as a categorical variable with strata of $<18$ years old, 18-35 years old, and $>35$ years old at the time of delivery. The state of maternal residence was limited to the 4 states in the study (KY, TN, VA, and $\mathrm{WV}$ ). While maternal race was entered in the analytic data set as white, black, or another, the analysis was limited to the non-Hispanic white. Birth year (1990-2002) entered as a continuous variable, and gestational age in weeks (22-44 weeks) entered as a categorical variable.

Paternal characteristics were not included in the analysis as the documentation was incomplete $(20-70 \%$ missing data), as was the average number of cigarettes (17\% missing data). Similarly, alcohol use was not included as it was markedly underreported $-1.5 \%$ prevalence compared to national rates of $16.3 \%$ [18]. Data on medical risk factors, e.g., diabetes, hypertension, and renal disease, was not extracted as it, unlike tobacco use, had not been validated from the birth certificate [19]. Thus, all analytic co-variables included in the analysis had individual data reported on at least $98 \%$ of the subjects.

\section{Data analysis}

Live births (4 states, 1990-2002) were aggregated to the county of maternal residency and then by mining activity for that county, i.e., counties with no mining activity, counties with only underground coal mining activity, and counties with mountain-top mining activity. Small-forgestational-age prevalence rates and prevalence rate ratios were calculated using Epi-Info7 [20] with a two-tailed $\mathrm{p}$-value $<0.05$ as the level of significance. Analyses compared rates for residents of mining counties with those for residents of non-mining counties. Analyses also compared rates for residents of mining counties with MTM activity with those for residents of mining counties without MTM activity. Similar analyses were conducted for prevalence of self-reported maternal tobacco use.

Logistic regression analytic models were developed using Stata SE-13 [21] with SGA as the dependent variable, mining activity group as the primary independent variable of interest, maternal tobacco use as the secondary independent variable of interest, and co-variables of maternal and infant risk factors as additional independent variables of interest. Logistic regression analyses yielded unadjusted (crude odds ratio - cOR), tobacco-adjusted, co-variableadjusted, and fully (tobacco and co-variables) adjusted odds ratios (aOR). Effects on the odds ratio of the addition of tobacco use and/or the co-variables to the models were demonstrated. Z-scores of independent variables were compared.

In order to assess whether the effect of tobacco use on SGA varied across the mining groups, gestational-age specific SGA prevalence rates for tobacco using and nontobacco using residents of each mining group were calculated and graphically compared.

\section{RESULTS}

The 4 state (KY, TN, VA, WV) live birth certificate (1990-2002) data file contained 3206343 live births, out of which 3067914 (95.7\%) met the Oken et al. crite- 
ria [15]. As the study population was the non-Hispanic white mothers, the major exclusion was for 762889 mothers (632 265 non-white and 130624 Hispanic-white), out of whom only $4 \%$ lived in the mining counties. Singleton live births totaled 2305025 (1 185159 males and 1119866 females) to non-Hispanic white mothers with known tobacco use histories served as our study population.

\section{SGA prevalence by mining group activity}

The overall SGA prevalence $(\%)$ in the four-state data set was $11.4 \%$; slightly higher than the $10 \%$ expected from the national data. The SGA prevalence was not uniform across the residential county mining activity groups (Table 1 ). Residents of counties with mining activity had a higher SGA prevalence (13.3\%) than did residents of counties with no mining activity (11\%). Residents of counties with MTM activity had a higher SGA prevalence (13.7\%) than did residents of non-MTM counties, i.e., with only underground mining activity $(12.9 \%)$.

The prevalence rate ratio $(\mathrm{PRR}=1.21,95 \%$ confidence interval (CI): 1.20-1.22) for counties with coal mining activity compared to residents of counties with no mining activity showed a $21 \%$ higher SGA prevalence. The prevalence rate ratio $(\mathrm{PRR}=1.07,95 \% \mathrm{CI}: 1.05-1.09)$ for counties with MTM coal mining activity compared to residents of non-MTM counties showed a 7\% higher SGA prevalence.

\section{Tobacco use by mining group activity}

Maternal tobacco use prevalence overall in the 4-state data sets was $20.8 \%$, but it ranged by mining group activity from $19.2 \%$ to $30.9 \%$ (Table 2 ). The maternal tobacco use prevalence was $19.2 \%$ in the non-mining counties and $28.3 \%$ in the mining counties (PRR $=1.47$, 95\% CI: 1.46-1.48), showing a nearly 50\% higher prevalence in the mining counties than in the non-mining counties.

Among the counties with mining activity, the maternal tobacco use prevalence was $25.8 \%$ in the counties with only non-MTM activity and $30.9 \%$ in the counties with MTM activity (PRR $=1.20,95 \%$ CI: 1.19-1.21), showing a $20 \%$ higher prevalence in counties with mining counties with MTM activity than in mining counties without MTM activity. The rate of tobacco use in counties with MTM coal mining (30.9\%) was higher than that of mining counties without MTM (25.8\%), which was higher than that in counties with no mining activity $(19.2 \%)$.

\section{Logistic regression model}

The logistic regression analysis was undertaken to examine the influence of the covariates on the estimation of the associations between SGA frequency and residency in the mining groups. Co-variables were extracted from the birth certificate form. Analyses were conducted both including and excluding tobacco use as a co-variable.

Table 1. Small-for-gestational age (SGA) prevalence by residential county mining activity, central Appalachian states, 1990-2002

\begin{tabular}{lcccc}
\hline & Activity & Live births & \multicolumn{3}{c}{ SGA } & \multirow{2}{*}{ PRR (95\% CI) } \\
\cline { 3 - 4 } & {$[\mathrm{n}]$} & $\mathrm{n}$ & $\%$ & \\
\hline Non-mining & 1914231 & 210125 & 11.0 & - \\
Mining & 390794 & 51939 & 13.3 & $1.21(1.20-1.22)$ \\
non-MTM & 201391 & 25906 & 12.9 & - \\
MTM & 189403 & 26033 & 13.7 & $1.07(1.05-1.09)$ \\
Total & 2305025 & 262064 & 11.4 & - \\
\hline
\end{tabular}

MTM - mountain-top mining.

PRR - prevalence rate ratio; $\mathrm{CI}$ - confidence interval. 
Table 2. Maternal tobacco use prevalence by residential county mining activity, central Appalachian states, 1990-2002

\begin{tabular}{lcccc}
\hline & Live births & \multicolumn{2}{c}{ Maternal tobacco use } & \multirow{2}{*}{ PRR (95\% CI) } \\
\cline { 3 - 4 } & An] & $\mathrm{n}$ & $\%$ & \\
\hline Non-Mining & 1914231 & 368047 & 19.2 & - \\
Mining & 390794 & 110514 & 28.3 & $1.47(1.46-1.48)$ \\
non-MTM & 201391 & 51918 & 25.8 & - \\
MTM & 189403 & 58596 & 30.9 & $1.20(1.19-1.21)$ \\
Total & 2305025 & 262064 & 11.4 & - \\
\hline
\end{tabular}

Abbreviations as in Table 1.

Table 3. Small-for-gestational age (SGA) odds ratios by residential county mining activity group - unadjusted, adjusted, and tobacco inclusion, central Appalachian states, 1990-2002

\begin{tabular}{lcccc}
\hline \multicolumn{1}{c}{ Model } & OR & $95 \%$ CI & $\mathrm{Z}$ & $\mathrm{p}$ \\
\hline $\begin{array}{l}\text { Mining vs. non-mining counties } \\
\text { unadjusted }\end{array}$ & 1.240 & $1.23-1.26$ & 41.45 & 0.000 \\
$\quad$ including tobacco & 1.120 & $1.10-1.13$ & 18.58 & 0.000 \\
$\quad$ adjusted* & 1.090 & $1.08-1.10$ & 13.57 & 0.000 \\
$\quad$ including tobacco & 1.060 & $1.05-1.08$ & 9.78 & 0.000 \\
Mining with vs. non-MTM & & & & \\
unadjusted & 1.080 & $1.06-1.10$ & 8.11 & 0.000 \\
$\quad$ including tobacco & 1.020 & $0.99-1.04$ & 1.94 & 0.052 \\
adjusted* & 1.040 & $1.02-1.07$ & 4.37 & 0.000 \\
$\quad$ including tobacco & 0.999 & $0.98-1.02$ & -0.07 & 0.941 \\
\hline
\end{tabular}

MTM - mountain-top mining.

OR - odds ratio; CI - confidence interval.

* Singleton births adjusted for child sex, prenatal care adequacy, maternal characteristics (married, age, education, foreign-born), state of residence, year of birth, and gestational age (weeks) in analysis for non-Hispanic white women.

The logistic regression analysis was conducted to determine the SGA odds ratio for residents of counties with mining activity (mining) as compared to that of residents of counties without mining activity (nonmining) (Table 3). The unadjusted crude odds ratio was 1.24 (95\% CI: 1.23-1.26). Adjustment only for tobacco use reduced the odds ratio to 1.12 (95\% CI: 1.10 $1.13)$, accounting for the reduction of $50 \%((1.12-1.24) /$ $(1.24-1.00)=-50 \%)$. Adjustment for all other co-variables except for tobacco use reduced the odds ratio to 1.09 (95\% CI: $1.08-1.10)$, accounting for the gross reduction of $64 \%$.

The full model including both tobacco use and the other co-variables yielded the odds ratio of 1.06 (95\% CI: 1.051.08 ), accounting for the total reduction of $75 \%$. Tobacco use accounted by itself for $50 \%$ of the excess odds ratio for mining counties and for $75 \%$ of the excess odds ratio with the other co-variables.

In the full model, the tobacco use odds ratio $(\mathrm{OR}=2.46$, $\mathrm{z}$-score $=186.6$ ) was far greater than that for mining 
counties $(\mathrm{OR}=1.06, \mathrm{z}$-score $=9.78)$. Other major risk factors were male child $(\mathrm{OR}=1.65$, z-score $=115.4)$, maternal education $\leq 12$ years $\mathrm{OR}=1.31$, $\mathrm{z}$-score $=$ 53.63), not married $(\mathrm{OR}=1.28$, z-score $=47.9)$, and adequacy of prenatal care $(\mathrm{OR}=1.20$, z-score $=35.39)$ (not shown).

A similar logistic regression analysis was conducted to determine the SGA odds ratio for residents of mining counties with mountain-top mining activity (MTM) as compared to residents of mining counties without mountain-top mining activity (non-MTM) (Table 3). The unadjusted crude odds ratio was 1.08 (95\% CI: 1.06-1.10) and with adjustment for tobacco use alone was reduced to an odds ratio of 1.02 (95\% CI: 1.00-1.04), accounting for the reduction of $75 \%$. Adjustment for all other co-variables, except for tobacco use, reduced the odds ratio to 1.04 (95\% CI: 1.02$1.07)$, accounting for the gross reduction of $50 \%$. The full model including both tobacco use and the other co-variables yielded the odds ratio of 0.999 (95\% CI: 0.98-1.02), accounting fully for the excess odds ratio. By itself, tobacco use accounted for $75 \%$ of the excess odds ratio for mining counties with MTM activities and for $100 \%$ with the other co-variables.

In the full model, the tobacco use odds ratio $(\mathrm{OR}=2.52$, z-score $=88.82$ ) was the strongest risk factor, while MTM mining had no contribution $(\mathrm{OR}=0.999$, $\mathrm{z}$-score $=-0.07)$. Other major risk factors were male child $(\mathrm{OR}=1.63$, z-score $=49.59)$, maternal education $\leq 12$ years $(\mathrm{OR}=1.30$, z-score $=20.99)$, not married $(\mathrm{OR}=1.22$, $\mathrm{z}$-score $=18.29)$, and adequacy of prenatal care $(\mathrm{OR}=1.21$, z-score $=16.92)$ (not shown $)$.

The analyses above indicate that maternal tobacco use is the major explanatory risk factor for SGA in these Appalachian states and that it explains most of the differences in SGA prevalence by mining activity and type of mining activity (MTM). No evidence of significant collinearity was found with a mean variance inflation factors (VIF) of 1.13 and a range of $1.00-1.35$.
SGA prevalence by maternal tobacco use, residential county mining activity group, and gestational age

The effect of tobacco use on the prevalence of SGA has been shown to be gestational-age-dependent, with a monotonic rise between weeks 33-37 and a more than doubling of the prevalence at weeks 37-44. We have examined the gestational-age effect of tobacco use on SGA prevalence to determine whether the pattern varies across the mining groups. The Figure 1 demonstrates that the gestational-age specific pattern for SGA prevalence stratified by tobacco use is essentially the same for each of the 3 groups of counties. In each case, the SGA prevalence rose from about 0.085 , or $8.5 \%$ for weeks 22 to 32 and then rose monotonically by week 37 to about a doubling or tripling to $0.20-0.26$, or $20-26 \%$. The increased risks of SGA were limited to those who had reported tobacco use, and was so for each of the 3 groups of counties.

The Figure 2 shows the differences in SGA prevalence between tobacco users and tobacco non-users by gesta-

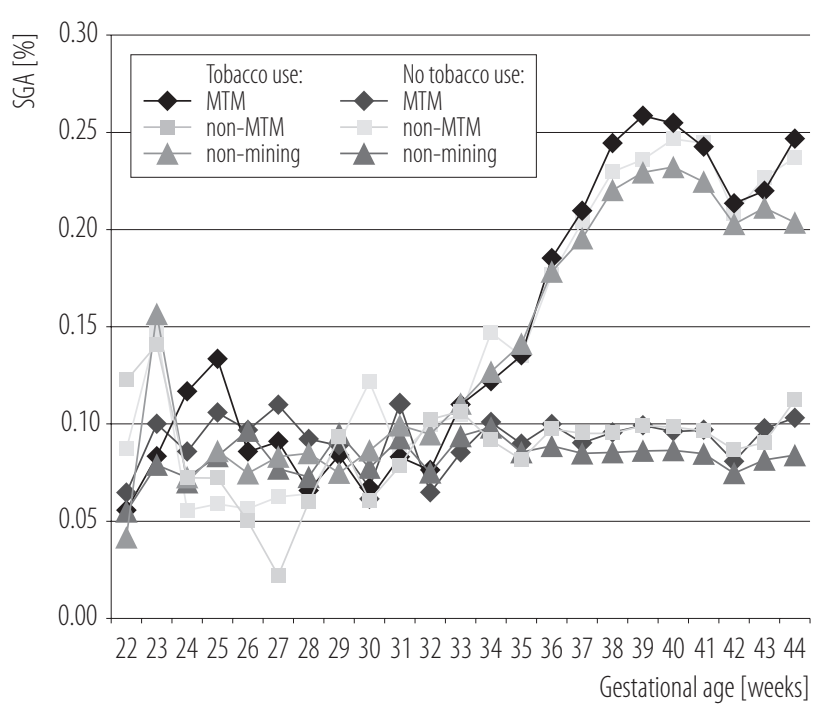

MTM - mountain-top mining.

Fig. 1. Small-for-gestational age (SGA) prevalence by gestational age, tobacco use, and mining activity, central Appalachian states, 1990-2002 


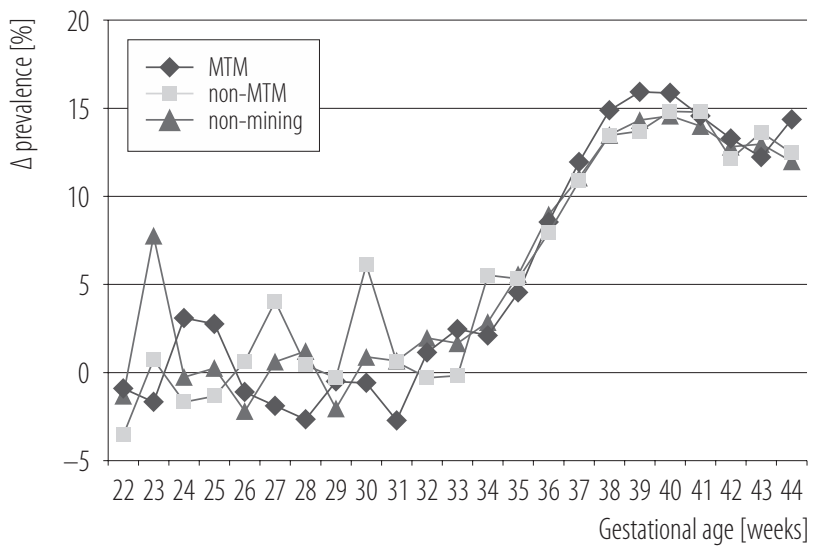

MTM - mountain-top mining.

Fig. 2. Difference $(\Delta)$ in small-for-gestational age (SGA) prevalence for tobacco users and non-users by gestational age and mining activity, central Appalachian states, 1990-2002

tional age at birth and by mining activity in the maternal county of residence, i.e., the tobacco-related increased risk of SGA. The gestational age pattern for the increased risk of SGA with tobacco use is similar for all 3 groups of counties, grouped by mining activity.

The overall SGA prevalence rates varied among the counties when grouped by mining activity with tobacco use being the major explanatory factor. Similarly, when SGA prevalence rates were examined by gestational age and tobacco use concurrently, the SGA prevalence rates by mining group were found to exhibit the same pattern with the tobacco effect by gestational age being the same.

\section{DISCUSSION}

The primary hypothesis investigated by this paper has been whether, in the four-state Appalachian area, the SGA prevalence is increased among infants born to women who have lived in the mining counties as compared to those who have lived in the non-mining counties, and whether prevalence rates are higher in mining counties with MTM as compared to mining counties without MTM. The data analysis has demonstrated, indeed, that the SGA prevalence rate is higher in either case.
The second task has been to determine to what degree these area differences could be explained by known risk factors and to what degree these differences are unexplained. Risk factor information was obtained from the birth certificate. The variable with the highest odds ratio was tobacco use. Its inclusion alone accounted for about $50-75 \%$ of the excess risk and in magnitude it was about equal to or greater than for all other risk factors.

The odds ratio for residents of mining counties as compared to residents of non-mining counties when adjusted for co-variables including tobacco use was reduced from 1.25 to 1.07 (95\% CI: $1.05-1.07$ ) and for residents of mining counties with MTM activity as compared to those of mining counties without MTM activity was reduced from 1.09 to 0.999 (95\% CI: 0.98-1.02) for residents mining counties with MTM activity as compared to those of mining counties without MTM activity. The significant differences in SGA prevalence by gestational age that were seen with tobacco use were the same in all 3 county groups and thus appeared to be uninfluenced by the presence of the mining activity in the counties.

The variables found on the birth certificate data set, particularly tobacco use, were sufficient to explain all of the differences in SGA prevalence for mining counties with and without MTM mining activity and three-quarters of the difference among mining counties and non-mining counties. It may be that further inclusion of known risk factors for SGA, such as maternal height and weight [22] or socioeconomic disadvantage [23], might explain much of the remaining differences.

We have used Oken et al. [15] rather than Olsen et al. [24] for the SGA cut-points. The Oken data has been developed from the same form (1989 U.S. live birth certificate) as has been our data - from more than 6.6 million live births, separated by race. They are recommended for vital statistics purposes by the Association of Maternal and Child Health Programs [25]. In contrast, the Olsen data, based on nearly 400000 hospital records of newborns 
discharged live from one large multi-hospital medical group (Pediatrix), had instead been designed for use in the neonatal intensive care unit (NICU) setting.

Our findings regarding tobacco use and SGA are consistent with a rather extensive literature that has generally shown a two-fold or greater risk of SGA with tobacco use for full-term births, and often a dose-response. Risks of 2-3 fold have been reported from Brazil [26], Switzerland [27], Finland [28], Boston [29], Japan [30], Portugal [31], Crete [32], and Sweden [33], and for Aboriginal Australia [34], African-Americans in North Carolina [35], Pacific Islanders [36], Canadian Inuit [37] and adolescents in New Jersey [38]. These compare with prevalence rate ratios of 2.60 for full-term births and 2.48 for all births in our data set (not shown).

Differences among these populations may reflect differences in dosage. Clausson et al. [39] in Sweden had shown a risk of 2.6 for $\geq 10$ cigarettes per day but of only 1.8 for smoking rates of 1-9 cigarettes per day. Mehaffey et al. [37] from the Baffin Island had shown a risk of 2.5 for $\geq 10$ cigarettes per day but no increase for lower dosages. Kalinka and Hanke [40] in Poland had shown a risk of 5 only for the infants of mothers who had smoked more than 20 cigarettes per day. Both McCowan et al. [22] and Vardavas et al. [32] had shown that the adverse effect of smoking on small for gestational age prevalence was not observed for those who had stopped smoking prior to the 15 th week of gestation.

The literature on the risk for SGA from maternal tobacco use among premature births is quite scant. Reported risks through the gestational age of 36 weeks include 1.5 (28-36 weeks), 1.85 (up to 36 weeks), and 2.23 (22-36 weeks) [33,41,42]. Our findings do not differ from those in the literature. Our data analysis (not shown) has found prevalence risk ratios of 1.07 for the gestational age of 22-32 weeks and of 1.70 for the gestational age of 33-36 weeks for an overall risk of 1.57 for premature births. Similar to our findings, Clausson et al. [39] also reported no increased risk of SGA from tobacco use for severely pre-mature births (up to week 32) and adjusted odds ratios of 1.7-1.9 for moderately premature births (gestational age: 33-36 weeks).

Our study confirms the literature observation first clearly demonstrated nearly 20 years ago in Sweden [39] smoking has no apparent effect on the prevalence of SGA prior to week 33 and a high risk for term babies (OR up to 2.6 for $>10$ cigarettes/day) and gestational age $\geq 37$ weeks, plus a lower rate for those with moderate prematurity (33-36 weeks).

Our analyses provide for the first time a quite granular look by respective weeks of gestational age and show no effect for tobacco use on SGA for the gestational age of 22-32 weeks births, a monotonically increase for the gestational age of 33-36 weeks births, and a steady 2-3 fold effect for $\geq 37$ weeks births, i.e., term births. This has been our primary contribution to the SGA epidemiological literature. In this paper, we find that the patterns are the same for the sets of counties aggregated by mining activity.

\section{Strengths and limitations}

Positive attributes of this study include that it is based on a full live birth cohort for a defined geographical region (four states of central Appalachia) and time period (1990-2002) with all data collected on the same standardized U.S. birth certificate. The gestational-weekspecific SGA cut-off values had been developed from a reference population (U.S. 1999-2002) that had used the same form [15]. The methods for measuring both birth weight and gestational age are standardized and have not altered during the period of the study. The analyses, while limited to singleton births with the gestational ages of 22-44 weeks for non-Hispanic white women, are based on over 2.3 million live births.

Limitations of this study include that the maternal tobacco use history was obtained by report or interview at 
the time of birth only. While maternal smoking histories on birth certificates were validated elsewhere [19], not here. Nielsen et al. had shown - for maternal smoking history on the Washington State birth certificate - a sensitivity of $85-89 \%$ and a specificity of $99 \%$ based on urinary cotinine measures [19].

Self-reporting could serve as a surrogate for a set of lifestyle factors that may also correlate with SGA, such as heavy alcohol drinking $[43,44]$ and the use of marijuana [45], cocaine [46], and opiates [47]. Out of these, opiate use is a particular problem in Appalachia [48].

Subsequent analyses might include alcohol use, the number of cigarettes per week, weight gain, diabetes, hypertension, and chronic kidney disease, items on the birth certificate but have not been included in these analyses, and county-specific socioeconomic co-variables such as income, poverty, and rural, which are not on the birth certificate were not included either.

As neither pre-pregnancy weight nor maternal height was included as a field on the birth certificate, it was not feasible to distinguish the constitutionally small-for-gestational age babies (i.e., small babies of small mothers) from the other SGA babies.

Exposure is limited to the county of residence as states would not release data at finer granularity for issues of privacy. Furthermore, routes of exposure, i.e., ingestion of water or soil or ingestion of air, are undefined and would be speculative with no proposed specific exposure agents and no specific exposure data.

\section{CONCLUSIONS}

In summary, this study demonstrates that the increased prevalence of SGA among residents of counties with mining activity has been greatly explained by the differences in maternal tobacco use prevalence, an effect that itself has been gestational-age dependent. No effect of maternal tobacco use on SGA prevalence has been seen prior to the gestational age of 33 weeks, from whence it rises monotonically to a 2-3-fold factor for full-term newborns. Seventy-five percent of the differences in SGA prevalence among counties with mining activity and those with no mining activity has been explained by tobacco use and demographic variables. One-hundred percent of the differences in SGA prevalence among mining counties with MTM mining activity and those without MTM mining activity have been explained by tobacco use and demographic variables.

The SGA prevalence rates by gestational age have not varied by mining activity group for both tobacco users and tobacco non-users. Tobacco use, not mining activity, has been the predominant variable explaining the differences in SGA prevalence in the study area.

\section{ACKNOWLEDGMENTS}

We thank Lu Qian for assistance in developing the analyses and manuscript.

\section{REFERENCES}

1. Center for Disease Control and Prevention [Internet]. Atlanta: The Center; 2015 [cited 2015 Mar 15]. National Center for Health Statistics. National Vital Statistics System: Birth datad 1990-2000. Available from: http://www.cdc.gov/nchs/data_access/Vitalstatsonline.htm\#Downloadable.

2. Hendryx M, Ahern M. Relations between health indicators and residential proximity to coal mining in West Virginia. Am J Public Health. 2008;98(4):669-71, https://doi.org/10.21 05/AJPH.2007.113472.

3. Esch L, Hendryx M. Chronic cardiovascular disease mortality in mountaintop mining areas of central Appalachian states. J Rural Health. 2011;27(4):350-7, https://doi.org/10.1111/ j.1748-0361.2011.00361.x.

4. Woolley SM, Meacheam SL, Balmert LC, Talbott EO, Buchanich JM. Comparison of mortality disparities in Central Appalachian coal- and non-coal-mining counties. J Occup Environ Med. 2015;57(6):687-94, https://doi.org/10.1097/ JOM.0000000000000435. 
5. U.S. Energy Information Administration [Internet]. Washington: The Administration; 2017 [cited 2014 Oct 10]. Coal. Available from: http://www.eia.gov/coal/data.cfm\#production.

6. Hendryx M. Mortality from heart, respiratory, and kidney disease in coal-mining areas of Appalachia. Int Arch Occup Environ Health. 2009;82(2):243-9, https://doi.org/10.1007/ s00420-008-0328-y.

7. Borak J, Salipante-Zaidel C, Slade MD, Fields CA. Mortality disparities in Appalachia: Reassessment of major risk factors. J Occup Environ Med. 2012;54(2):146-56, https://doi. org/10.1097/JOM.0b013e318246f395.

8. Buchanich JM, Balmert LC, Youk AO, Wooley SM, Talbott EO. General mortality patterns in Appalachian coal mining and non-coal mining counties. J Occup Environ Med. 2014;56(11):1169-78, https://doi.org/10.1097/JOM.00 00000000000245 .

9. Ahern MM, Hendryx M, Conley J, Fedorko E, Ducatman A, Zullig KJ. The association between mountaintop mining and birth defects among live births in central Appalachia, 1996-2003. Environ Res. 2011;111:838-46, https://doi.org/ 10.1016/j.envres.2011.05.019.

10. Ahern M, Mullett M, Mackay K, Hamilton C. Residence in coal-mining areas and low-birth-weight outcomes. Maternal Child Health J. 2011;15(7):974-9, https://doi.org/10.1007/ s10995-009-0555-1.

11. World Health Organization. Children's environmental health indicators: Indicators to improve children's environmental health - Intrauterine growth retardation in newborn [Internet]. Geneva: The Organization; 2015 [cited 2015 Mar 15]. Available from: http:/www.who.int/ceh/indicators/iugrnewborn.pdf.

12. Ferdosi H, Afari-Dwamena NA, Dissen E, Li J, Chen R, Feinleib M, et al. Maternal tobacco use as a risk factor for small for gestational age (SGA) is a third-trimester effect. In: Euroscicon. Smoking science summit; 2015 May 19-21; London, United Kingdom.

13. Williams RL, Creasy RK, Cunningham GC, Hawes WE, Norris FD, Tashiro M. Fetal growth and perinatal viability in California. Obstet Gynecol. 1982;59:624-32.
14. Word Health Organization Expert committee report: Physical status: The use and interpretation of anthropometry. Geneva: The Organization; 1995.

15. Oken E, Kleinman KP, Rich-Edwards J, Gillman MW. A nearly continuous measure of birth weight for gestational age using a United States national reference. BMC Pediatrics. 2003;3:6, https://doi.org/10.1186/1471-2431-3-6.

16. Centers of Disease Control and Prevention [Internet]. Atlanta: The Centres; 2017 [cited 2015 Apr 24]. Linked birth / infant death records, 1995-1998. Available from: http://wonder.cdc.gov/lbd-icd9.html.

17. Kessner DM, Singer J, Kalk CE, Schlesinger ER. Infant death: An analysis by maternal risk and health care. Contrasts in health status. Vol. I. Washington: Washington Institute of Medicine, National Academy of Sciences; 1973.

18. Centers for Disease Control and Prevention. Alcohol use among women of childbearing age - United States, 19911999. MMWR Morb Mortal Wkly Rep. 2002;51:273-76.

19. Nielsen SS, Dills RL, Glass M, Mueller BA. Accuracy of prenatal smoking data from Washington State birth certificates in a population-based sample with cotinine measurements. Ann Epidemiol. 2014;24(3):236-9, https://doi.org/10.1016/ j.annepidem.2013.12.008.

20. Dean AG, Arner TG, Sunki GG, Friedman R, Lantinga M, Sangam S, et al. Epi Info ${ }^{\mathrm{TM}}$, a database and statistics program for public health professionals. Atlanta: Centers for Disease Control and Prevention; 2011.

21. Stata Statistical Software: Release 13 [computer program]. College Station (TX): StataCorp LP, 2013.

22. McCowan LM, Dekker GA, Chan E, Stewart A, Chappell LC, Hunter M, et al. Spontaneous preterm birth and small for gestational age infants in women who stop smoking early in pregnancy: Prospective cohort study. BMJ. 2009;338:b1081, https://doi.org/10.1136/bmj.b1081.

23. Beard JR, Lincoln D, Donoghue D, Taylor D, Summerhayes R, Dunn TM, et al. Socioeconomic and maternal determinants of small-for-gestational age births: Patterns of 
increasing disparity. Acta Obstet Gynecol Scand. 2009;88 (5):575-83, https://doi.org/10.1080/00016340902818170.

24. Olsen IE, Groverman SA, Lawson ML, Clark RH, Zemel BS. New intrauterine growth curves based on United States data. Pediatrics. 2010;125:214-24, https://doi.org/10.1542/ peds.2009-0913.

25. Association of Maternal Child Health Programs Life course indicator: Small for gestational age (LC-11) [Internet]. Washington: The Association; 2014 [cited 2015 May 20]. Available from: http://www.amchp.org/programsandtopics/dataassessment/LifeCourseIndicatorDocuments/LC-11\%20 Small\%20for\%20Gestational\%20Age_Final_9-8-2014.pdf.

26. Horta BL, Victoria CG, Menezes AM, Halpern R, Barros FC. Low birth weight, preterm births, and intrauterine growth retardation in relation to maternal smoking. Paediatr Perin Epidemiol. 2014;11(2):140-51, https://doi. org/10.1046/j.1365-3016.1997.d01-17.x.

27. Chiolero A, Bovet P, Paccaud F. Association between maternal smoking and low birth weight in Switzerland: The EDEN Study. Swiss Med Wkly. 2005;135(35-36):525-30, https://doi.org/2005/35/smw-11122.

28. Raatikainen K, Huurinainen P, Heinonen S. Smoking in early gestation or through pregnancy: A decision crucial to pregnancy outcome. Prev Med. 2007;44(1):59-63, https:// doi.org/10.1016/j.ypmed.2006.07.017.

29. Lang JM, Lieberman E, Cohen A. A comparison of risk factors for preterm labor and term small-for-gestational-age birth. Epidemiology. 1996;7(4):369-76.

30. Suzuki K, Tanaka T, Kondo N, Minai J, Sato M, Yamagata Z. Is maternal smoking during early pregnancy a risk factor for all low birth weight infants? J Epidemiol. 2008;18(3):89-96, https://doi.org/10.2188/jea.JE2007415.

31. Rodrigues T, Barros H. Comparison of risk factors for smallfor-gestational-age and preterm in a Portuguese cohort of newborns. Maternal Child Health J. 2007;11(5):417-24, https://doi.org/10.1007/s10995-007-0195-2.

32. Vardavas CI, Chatzi L, Patelarou E, Plana E, Sarri K, Kafatos $\mathrm{A}$, et al. Smoking and smoking cessation during early pregnancy and its effects on adverse pregnancy outcomes and fetal growth. Eur J Pediatr. 2010;169(6):741-8, https:// doi.org/10.1007/s00431-009-1107-9.

33. Baba S, Wikstrom AK, Stephansson O, Cnattingius S. Changes in snuff and smoking habits in Swedish pregnant women and risk for small for gestational age births. BJOG. 2013;120(4):456-62, https://doi.org/10.1111/1471-05 28.12067.

34. Chan A, Keane RJ, Robinson JS. The contribution of maternal smoking to preterm birth, small for gestational age and low birthweight among Aboriginal and non-Aboriginal births in South Australia. Med J Aust. 2001;174(8):389-93.

35. Savitz DA, Dole N, Terry JW Jr., Zhou H, Thorp JM Jr. Smoking and pregnancy outcome among African-American and white women in central North Carolina. Epidemiology. 2001;12(6):636-42, https://doi.org/10.1097/00001648200111000-00010.

36. Gao W, Paterson J, Carter S, Percival T. Risk factors for preterm and small-for-gestational-age babies: A cohort from the Pacific Islands families study. J Paediatr Child Health. 2006;42: 785-92, https://doi.org/10.1111/j.1440-1754.2006.00978.x.

37. Mehaffey K, Higginson A, Cowan J, Osborne GM, Arbour LT. Maternal smoking at first prenatal visit as a marker of risk for adverse pregnancy outcomes in the Qikiqtaaluk (Baffin) Region. Rural Remote Health. 2010;10(3):1484.

38. Scholl TO, Salmon RW, Miller LK. Smoking and adolescent pregnancy outcome. J Adolesc Health Care. 1986;7(6): 390-4, https://doi.org/10.1016/S0197-0070(86)80240-6.

39. Clausson B, Cnattingius S, Axelsson O. Preterm and term births of small for gestational age infants: A populationbased study of risk factors among Nulliparous women. BJOG. 1998;105:1011-17, https://doi.org/10.1111/j.1471-0528. 1998.tb10266.x.

40. Kalinka J, Hanke W. Tobacco smoking - A risk for intrauterine growth retardation, preterm delivery and low birth weight. Ginekol Pol. 1996;67(2):75-81.

41. Polakowski LL, Akinbami LJ, Mendola P. Prenatal smoking cessation and the risk of delivering preterm and 
small-for-gestational-age newborns. Obstet Gynecol. 2009; 144(2):318-25, https://doi.org/10.1097/AOG.0b013e318 1ae9e9c.

42. Taylor LK, Lee YY, Lim K, Simpson JM, Roberts CL, Morris J. Potential prevention of small for gestational age in Australia: A population-based linkage study. BMC Pregnancy Childbirth. 2013;13:210, https://doi.org/10.1186/14712393-13-210.

43. Patra J, Bakker R, Irving H, Jaddoe VWV, Mailini S, Rehm J. Dose-response relationship between alcohol consumption before and during pregnancy and the risks of low birth weight, preterm birth, and small-size-for-gestational age (SGA) - A systematic review and meta-analysis. BJOG. 2011;118(12):1411-21, https://doi.org/10.1111/j.1471-0528.20 11.03050.x.

44. Aliyu MH, Wilson RE, Zoorah R, Brown K, Alio AP, Clayton $\mathrm{H}$, et al. Prenatal alcohol consumption and fetal growth restriction: Potentiation effect by concomitant smoking.
Nicotine Tob Res. 2009;11(1):36-43, https://doi.org/10.1093/ ntr/ntn014.

45. Hayatbakhsh MR, Flenady VJ, Gibbons KS, Kingsbury AM, Hurrion E, Mamun AA, et al. Birth outcomes associated with cannabis use before and during pregnancy. Pediatr Res. 2012;71(2):215-9, https://doi.org/10.1038/pr.2011.25.

46. Kistin N, Handler A, Davis F, Ferre C. Cocaine and cigarettes: A comparison of risks. Paediatr Perinat Epidemiol. 1996;10(3):269-78, https://doi.org/10.1111/j.1365-3016.1996. tb00050.x.

47. Cleary BJ, Eogan M, O'Connell MP, Fahey T, Gallagher PJ, Clarke T, et al. Methadone and perinatal outcomes: A prospective cohort study. Addiction. 2012;107(8):1482-92.

48. Shannon LM, Havens JR, Mateyoke-Scrivner A, Walker R. Contextual differences in substance use for rural Appalachian treatment-seeking women. Am J Drug Alcohol Abuse. 2009;35(2):59-62, https://doi.org/10.1080/0095299080 2441394.

This work is available in Open Access model and licensed under a Creative Commons Attribution-NonCommercial 3.0 Poland License - http://creativecommons.org/ licenses/by-nc/3.0/pl/deed.en. 